\title{
UMA REFLEXÃO SOBRE A CONSTRUÇÃO DE SENTIDO NA PERFORMANCE MUSICAL PELA PERSPECTIVA DO INTÉRPRETE DE MÚSICA INDETERMINADA
}

\section{A REFLECTION ABOUT THE CONSTRUCTION OF MEANING IN MUSICAL PERFORMANCE FROM THE PERSPECTIVE OF THE INDETERMINATE MUSIC PERFORMER}

\author{
Ana Leticia Crozetta Zomer \\ Universidade de São Paulo \\ analeticiazomer@gmail.com
}

\section{Resumo}

Este trabalho é um desdobramento da pesquisa de doutorado ainda em andamento, intitulada Acaso e indeterminação na música brasileira: uma análise do repertorio violinístico após 1950. Aqui, discutiremos a genealogia do conceito de obra musical até sua cristalização por volta de 1800 e seus reflexos no desenvolvimento da notação e performance musical; as transformações estéticocomposicionais que surgiram a partir da segunda metade do século XX e suas principais vertentes; e por fim, procuramos oferecer uma breve reflexão sobre a construção de sentido na performance musical pela perspectiva do intérprete de música indeterminada, ou seja, aquela que está sujeita a múltiplas interpretações e relações intersubjetivas. Três trabalhos nos deram suporte filosófico: The Imaginary Museum of Musical Works (1992) de Lydia Coehr, que se empenhou em traçar a genealogia do conceito de obra musical; Estética: Teoria da Formatividade (1993) de Luigi Pareyson, em que o autor analisa a obra de arte a partir de um ponto de vista formativo - a obra como um objeto em construção e em permanente formação; e Obra Aberta (2003) de Umberto Eco, que apresenta estreita relação com a leitura anterior e trata, entre outras coisas, da dicotomia entre obra aberta e fechada.

Palavras-chave: Música do Século XX; Indeterminação; Performance Musical; Cenealogia do Conceito de Obra; Notação musical. 


\begin{abstract}
This work is an offshoot of the ongoing doctoral research entitled, Acaso e indeterminação na música brasileira: uma análise do repertorio violinistico após 1950. Here we will discuss the genealogy of the concept of musical work until its crystallization around 1800 and its reflections on the development of musical notation and performance; the aestheticcompositional transformations that emerged from the second half of the twentieth century and its main aspects; finally, we seek to offer a brief reflection on the construction of meaning in musical performance from the perspective of the indeterminate music interpreter, that is, the one that is subject to multiple interpretations and intersubjective relations. Three works provided us philosophical support: Lydia Goehr's The Imaginary Museum of Musical Works (1992), which endeavored to trace the genealogy of the concept of musical work; Estética: Teoria da Formatividade (1993) by Luigi Pareyson, in which the author analyzes the work of art from a formative point of view - the work as an object under construction and in permanent formation; and Obra Aberta by Umberto Eco (2003), which presents a close relationship with the previous reading and deals, among other things, with the dichotomy between open and closed work.
\end{abstract}

Keywords: 20th Century Music; Indeterminacy; Musical Performance; Genealogy of the Concept of Work; Musical Notation.

\title{
1. Introdução
}

Apesar de sua forte tradição textual, a música de concerto ocidental tem sido gradualmente aceita como expressão, apresentando alto grau de dinamismo e variabilidade por conta de sua dimensão performativa (cf. ALMEIDA, 2011 ). No entanto, a performance musical é um assunto muito pouco discutido pela literatura musical, "a não ser no sentido limitado de seguir as notações do compositor e percebê-las no som" (SMALL, 1998, p. 5, tradução nossa)!

I "We read little in music literature about performance other than in the limited sense of following the composer's notations and realizing them sound" (SMALL, 1998, p. 5). 
Este trabalho é um desdobramento da pesquisa de doutorado ainda em andamento, intitulada Acaso e indeterminação na música brasileira: uma análise do repertório violinístico após 1950. Aqui, discutiremos a genealogia do conceito de obra musical até sua cristalização por volta de 1800 e seus reflexos no desenvolvimento da notação e performance musical; as transformações estéticocomposicionais que surgiram a partir da segunda metade do século XX e suas principais vertentes; e por fim, procuramos oferecer uma breve reflexão sobre a construção de sentido na performance musical pela perspectiva do intérprete de música indeterminada, ou seja, aquela que está sujeita a múltiplas interpretações e relações intersubjetivas. Três trabalhos nos deram suporte filosófico: The Imaginary Museum of Musical Works ( 1992) de Lydia Coehr, que se empenhou em traçar a genealogia do conceito de obra musical; Estética: Teoria da Formatividade (1993) de Luigi Pareyson, em que o autor analisa a obra de arte a partir de um ponto de vista formativo - a obra como um objeto em construção e em permanente formação; e Obra Aberta (2003) de Umberto Eco, que apresenta estreita relação com a leitura anterior e trata, entre outras coisas, da dicotomia entre obra aberta e fechada.

\section{O conceito de "obra" e seus desdobramentos}

Na música de concerto ocidental, o conceito de obra musical sofreu importantes transformações ao longo da história. Essas transformações definiram regulamentos, expectativas e padrões de comportamento que caracterizaram sua prática. Em The Imaginary Museum of Musical Works (1992), Lydia Goehr empenhou-se em traçar a genealogia desse conceito. Para a autora, a música instrumental era predominantemente entendida e regulada por conteúdos de qualidade extramusicais. $\bigcirc$ conceito de obra não regulava a prática, existindo implicitamente durante o ato performático.

Foi por volta de 1800, mediante transformações no entendimento da teoria estética, da sociedade e política, que uma nova concepção emergiv, abrangendo a criação, performance e recepção. $\bigcirc$ novo 
conceito recebeu um papel regulador e limitador? "A produção musical passou a ser vista como o uso de material musical, resultando em unidades completas e discretas, originais e fixas, de propriedade pessoal" (COEHR, 1992, p. 206, tradução nossa) ${ }^{3}$. Assim, o conceito cristalizouse sob o que muitos teóricos da época chamavam de "princípio da separabilidade". Este princípio se refere às emancipações variadas da música instrumental e suas correlações.

A pretensa autonomia das belas-artes, garantida pela sua colocação em museus, levantou problemas particularmente interessantes para a música. Isso se torna evidente à medida que começamos a refletir como a música chegou a reproduzir algumas das características das artes plásticas, da pintura e da escultura. Ao ingressar no mundo das belas-artes, a música necessitava encontrar uma mercadoria plástica ou equivalente, um produto valioso e permanentemente existente, que pudesse ser tratado da mesma maneira que os objetos das já respeitáveis belasartes (COEHR, 1992, p. 173, tradução nossa)4.

A busca por uma "mercadoria plástica ou equivalente" ao das artes plásticas contribui para o surgimento da partitura. A música, que até então era uma manifestação quase que exclusiva da cultura oral, passou a ser registrada em documento físico e passível de distribuição em larga escala através de um mercado editorial em ascensão. "As obras musicais começaram a ser comercializadas da mesma forma que as belas-artes, em termos estéticos, a serem valorizadas e contempladas

2 "Now we can make sense of the basic argument lying behind my central claim that prior to 1800 (or thereabouts), musicians did not function under the regulation of the work-concept. To be sure, they functioned with concepts of opera, cantata, sonata, and symphony, but that does not mean they were producing works. It was only later when the production of music began to be conceived along work-based principles that early operas, cantatas, symphonies, and sonatas acquired their status as different kinds of musical work. And this is why we can meaningfully say, nowadays, that Bach composed musical works" (COEHR, 1992, p. 115).

3 "musical production was now seen as the use of musical material resulting in complete and discrete, original and fixed, personally owned units" (COEHR, 1992, p. 206).

4 "The purported autonomy of the fine arts, guaranteed by their placement in museums, raised particularly interesting problems for music. These become apparent as we begin to consider how music came to replicate some of the characteristics of the plastic arts of painting and sculpture. As it entered the world of fine arts, music had to find a plastic or equivalent commodity, a valuable and permanently existing product, that could be treated in the same way as the objects of the already respectable fine arts" (COEHR, 1992, p. 173).

\section{2}

REV. TULHA, RIBEIRÃO PRETO, v. 5, n. 1, pp. 9-32, jan.-jun. 2019 
como criações permanentemente existentes de compositores/artistas" (COHER, 1992, 174, tradução nossa) ${ }^{5}$. Logo, a partitura alcançou uma classe consumidora específica, qualificando-a como bem de consumo. As artes plásticas existentes em seus museus físicos e, portanto, as obras musicais existentes em museus imaginários.

\begin{abstract}
É por causa desse significado imutável e imanente que pinturas, livros, peças de escultura e outros objetos de arte (incluindo obras musicais e partituras que, não se sabe bem o porquê, deveriam ser os portadores delas); são cuidadosamente exibidos em museus com ar-condicionado (e salas de concerto), vendidos por preços exorbitantes (a partitura autografada do Concerto para Piano em Lá Menor de Schumann foi vendida em Londres em 1989 por quase um milhão e meio de dólares), impressa em edições luxuosas, com o manuscrito do compositor (e performada em versões "autênticas") (SMALL, 1998, p. 5, tradução nossa)6.
\end{abstract}

Consequentemente, a notação passou por um crescente processo de especialização técnica, atingindo um grande rigor a fim de alcançar um suposto resultado sonoro estrito e invariável. De acordo com Coehr (1992) a necessidade de uma especialização da escrita musical se tornou urgente, principalmente quando a música começou a ser executada independentemente da presença do compositor e quando a mesma composição passou a ser reproduzida inúmeras vezes, tornando os estilos mais pessoais. Logo, o intérprete se tornou mão-de-obra qualificada e especializada através da formação em conservatórios. "O músico prático perdeu sua parte criativa quase que inteiramente para o compositor e se tornou um intérprete. Com isso, estabeleceu-se a

5 "Musical works also began to be marketed in the same way as other works of fine art and, in aesthetic terms, to be valued and contemplated as permanently existing creations of composers/artists" (COEHR, 1992, p. 174).

6 "It is the sake of that unchanging, immanent meaning that paintings, books, pieces of sculpture and other art objects (including musical works and the scores that in some not quite understood way are supposed to be the bearers of them) are cared for, lovingly exhibited in air-conditioned museums (and concert halls), sod for exorbitant prices (the autograph score of Schumann's Piano Concerto in A Minor was sold in London in 1989 for nearly on and a half million dollars), printed in luxurious editions, pursued to the creator's manuscript (and performed in 'authentic' versions)" (SMALL, 1998, p. 5).

\title{
13
}

REV. TULHA, RIBEIRÃO PRETO, v. 5, n. 1, pp. 9-32, jan.-jun. 2019 
norma de se aderir exatamente à figura de nota e tornar inalterável o que estava prescrito" (WIORA, 1965, p. 132, tradução nossa)?

\begin{abstract}
A notação ocidental tende para uma figura de nota grafada, um desenho que chama a atenção. É um "desenho" da composição com seus altos e baixos na melodia e suas vozes mais altas e mais baixas em contraponto. Assim, é visível e abstrato ao mesmo tempo: "abstração visível", como um mapa (UIORA, 1965, p. 131 , tradução nossa) ${ }^{8}$.
\end{abstract}

Assim, ocorreu um processo de separação cada vez maior das funções compositor e intérprete. Diminuiu-se a mediação humana e afastou-se o objeto de seu contexto. De acordo com Deliège apud Costa (2009), isso ocorreu devido à progressiva divisão do trabalho após a Revolução Industrial e ao advento do pensamento liberal que levou o compositor à condição de "profissional liberal, dependente de um agente".

Importante lembrar que na música ocidental o impulso criativo do instrumentista se colocava presente de diferentes formas em épocas distintas da história, caracterizando-se pela liberdade de interpretação devido à maneira aproximativa como a música era notada, porém, tais "atos de liberdade consciente" (POUSSEUR apud ECO, 2003, p. 4l) estavam sujeitos a um universo estilístico e a um conjunto de regras em constante negociação com a liberdade dos músicos.

Sem dúvida a música europeia anterior ao século XVIII conheceu várias formas inacabadas, mas que não eram menos determinadas. Esse acabamento é virtual, sempre implícito e obedece a normas bem precisas. Se alguma liberdade estilística subsiste no responsável pela execução, jamais isto porá em causa a base morfológica e sintática e nem mesmo a infraestrutura formal (DELIËCE, 1971, p.156 apud COSTA, 2009, p. 18).

7 "The practical musician lost his creative share almost wholly to the composer and became an interpreter. With this was established the norm of adhering exactly to the note-picture and rendering unaltered what was there prescribed" (WIORA, 1965, p. 132).

8 "Western notation tend towards a graphic note-picture, a design to strike the eye. It is a 'drawing' of the composition with its ups and downs in melody and its higher and lower voices in counterpoint. Thus it is visible and abstract at the same time: "visible abstraction', like a map" (UIORA, 1965, p. 131 ). 
Como diz Bojan Bujic (apud Cook, 2013, p. 11, tradução nossa)9, “todo o curso subsequente da notação ocidental representa um afastamento da memória em direção ao estado em que um documento escrito pode representar, por assim dizer, a obra como tal". A escrita musical tornou-se um elemento determinante no estabelecimento de parâmetros composicionais, estéticos e performáticos. Tornou possivel - fortalecimento das teorias e transformou a partitura em um objeto autossuficiente que poderia ser estocado, distribuido e comparado. "Significou um passo importante na difusão de composições musicais entre as pessoas, outros países, partes do mundo e futuro adentro" (WIORA, 1965, p. 131 , tradução nossa) 10 . Criou-se "um imenso campo de diálogo e articulação entre compositores, intérpretes, estudiosos e, sobretudo, entre épocas musicais distintas" (ALMEIDA, 201 1, p. 65).

Onde antes era "um cenário neutro, não concebido para instrumentos específicos [...] agora se tornava um opus completamente especificado em que o timbre era tão passível de composição quanto a estrutura tonal" (WIORRA, 1965, p. 133, tradução nossa) ${ }^{\prime \prime}$. A excessiva valorização da partitura "é a confusão entre partitura e obra, ou seja, a idolatria ao texto, a crença de que ele se basta por supostamente comportar e cristalizar todos os aspectos do que se entende por obra musical [...], entendida como texto é considerada objeto estático" (ALMEIDA, 2011, p. 66). Entretanto, o controle de todas as variáveis presentes numa performance é algo que escapa a qualquer tipo de notação.

De fato, é difícil negar o valor da partitura como suporte eficaz de aspectos estruturantes e normativos de uma obra musical, mas é inegável que a abordagem de uma obra se aprofunda ao considerar não apenas o que nela há de texto fixo, mas também sua instabilidade que proporciona uma multiplicidade de resultantes interpretativas a partir de uma única partitura (ALMEIDA, 2011, p. 66).

\footnotetext{
9 "'the whole subsequent course of Western notation represents a move away from memory towards the state in which a written document can stand on its own, as it were, representing the work as such and offering to the performer clear indications how to recreate it in musical sounds"' (COOK, 2013, p. I1).

10 "Printing meant an important step in the diffusion of musical compositions among the people, in other countries and parts of the world, and into the future" (WIORA, 1965, p. 13 I). 1 I "Instead of a neutral setting, not conceived for particular instruments [... ], it now became the fully specified opus in which timbre was just as much composed as the tonal structure" (UIORRA, 1965, p. 133).
} 


\title{
3. Indeterminação em música e a desconstrução da própria noção de obra
}

\begin{abstract}
Quando os músicos trazem acontecimentos fora das salas de concerto, quando eles sugerem que o público traga instrumentos para tocar em momentos musicais, assim como artistas, quando se recusam a produzir partituras ou gravações para impedir a possibilidade de a música sobreviver à ocasião, quando enfatizamos que uma performance é um fim em si mesma e não apenas um canal através do qual um trabalho flui $e$, quando não impõem limites temporais em uma performance, afinal, parece que estamos observando desafios diretos ao conceito tradicional de obra. Pois não apenas os músicos dizem que estão desafiando o conceito, mas suas direções também têm a intenção explícita de minar as condições tradicionais e formais associadas à música baseada na obra (COEHR, 1992, p. 268, tradução nossa) ${ }^{12}$.
\end{abstract}

No século XX, experiências voltadas à busca por sonoridades não convencionais, levaram ao surgimento de tendências composicionais e ideológicas a elas inerentes. Compositores como John Cage, Karlheiz Stockhausen, Morton Feldman, Christian Wolff, Earle Brown e Pierre Boulez, procurando por novas possibilidades de composição, execução e percepção de uma obra musical, encontraram nos processos de utilização do acaso um argumento que se tornou uma das correntes musicais mais significativas no pós-guerra (cf. MORGAN, 1991, p. 359).

Diferentes tentativas de libertar o intérprete da exatidão ditada pela notação tradicional foram manifestas (cf. ANTOKOLETZ, 1992, p. 474). $\bigcirc$ emprego de clusters e a eliminação da barra de compasso em obras, como as de Charles Ives, Henry Cowell e Erik Satie, por exemplo, resultaram em um determinado grau de indeterminação harmônica e

12 "When musicians bring about happenings outside concert halls, when they suggest audiences bring instruments to play at musical occasions so as to be performers as well, when they refuse to produce scores or recordings to foreclose the possibility of the music's surviving past the occasion, when they stress that a performance is an end in itself and not merely a channel through which a work flows, and when they impose no temporal limits on a performance, we do, after all, seem to be observing direct challenges to the traditional work-concept. For not only do the musicians say they are challenging the concept, but their directions are also explicitly intended to undermine the traditional, formal conditions associated with work-based music" (COEHR, 1992, p. 268).

\section{6}

REV. TULHA, RIBEIRÃO PRETO, v. 5, n. 1, pp. 9-32, jan.-jun. 2019 
rítmica, enquanto que o uso do sprechstimme permitiu um determinado grau de indeterminação das alturas de obras como Pierrot Lunaire (1912) de Arnold Schoenberg. Possibilidades mais radicais também já estavam implícitas nos primeiros experimentos futuristas, tal como o controle do compositor sobre a unificação estrutural da obra através da manipulação do ruído.

No entanto, a partir de 1950, com o surgimento de uma base filosófica mais claramente definida, a utilização do acaso como recurso composicional deliberado ganha força e em grande parte por influência de um único compositor: John Cage ${ }^{\text {? }}$.

Esta nova poética se distingue por manifestar a consciência do elemento acaso durante o processo do fazer musical, seja ele compositivo e/ou interpretativo. Quando presente no fazer compositivo, é característica elementar a fixação de elementos musicais escolhidos por meio de procedimentos randômicos. A performance se mantém determinada através de uma notação precisa, sem alterações significativas no ato da performance. Quando presente no fazer interpretativo, é legado ao intérprete níveis de liberdade a fim de remodelar o resultado sonoro através da escolha de elementos no momento da execução. Busca-se um discurso que tem como resultado a variabilidade interpretativa. Definidos conceitualmente por John Cage ${ }^{14}$,

13 "Ele foi um dos poucos indivíduos de quem se pode dizer, sem contestação, que se ele não existisse, o desenvolvimento de mais de uma arte teria sido diferente" (KOSTELANETZ, 1993, p. 33, tradução nossa). John Milton Cage Jr. nasceu em Los Angeles, Califórnia, em 1912. Estudou com Henry Cowell, Adolph Weiss e Arnold Schoenberg. Compôs, aproximadamente, 315 obras para as mais diversas formações instrumentais. Cage transitou por diferentes poéticas, mas foi em 1951, que o compositor compõe a Music of Changes, considerada a primeira obra a fazer uso de operações de acaso como recurso composicional.

I4 No decorrer deste trabalho, observaremos que há diferentes maneiras de conceber o emprego do acaso na criação musical, portanto, essa tendência estético-composicional abrange uma série de concepções e discussões terminológicas: indeterminação, acaso, aleatoriedade, improvisação, acaso dirigido, obra aberta e outras. Dada a ampla dimensão a respeito da discussão terminológica, optamos para este trabalho, utilizar a nomenclatura sugerida por John Cage, considerado o precursor dessa tendência estético-composicional. $\bigcirc$ compositor procurou definir os aspectos dessa música em três conferências proferidas em Darmstadt (1958) na Alemanha, intituladas: Changes, Indeterminacy e Communication. Transcritas em Silence (1973), as conferencias serviram como referência terminológica para compreender a estética utilizada por alguns compositores, principalmente aos vinculados à chamada Escola de Nova York. Porém, os termos e suas definições variam de autor para autor, por exemplo, o termo indeterminação é empregado por John Cage para se referir às músicas que são parciais ou totalmente indeterminadas, desde Bach até os compositores contemporâneos. Para Francis Bayer, o mesmo termo é utilizado de forma mais restrita, para caracterizar a corrente estética em que o uso de elementos indeterminados produz uma ruptura de sentido e a recusa da noção de obra (TERRA, 2000, p. 135).

\section{7}

REV. TULHA, RIBEIRÃO PRETO, v. 5, n. 1, pp. 9-32, jan.-jun. 2019 
'acaso' se refere ao uso de certos procedimentos randômicos no ato da composição. [...] 'Indeterminação', por outro lado, se refere à habilidade de uma peça ser tocada de modos substancialmente diferentes - ou seja, a obra existe de tal forma que ao intérprete é dada uma variedade de maneiras únicas de tocá-la (PRITCHETT, 1993, p. 108, tradução nossa) $)^{15}$.

A proposição a respeito do papel aparentemente passivo do compositor frente ao resultado musical foi tema central de divergencias, especialmente, entre dois expoentes desta poética: Pierre Boulez e John Cage ${ }^{16}$. A utilização do acaso como recurso composicional por Boulez visou, por um lado, ampliar as possibilidades de permutação geradas pela série e por outro, definir os limites interpretativos a fim de assegurar a integridade da obra. Para o compositor, independente do recurso composicional utilizado, desviar-se da responsabilidade sobre - resultado sonoro mascara uma deficiência técnico-composicional, chamada por ele de "acaso por inadvertência" ${ }^{7}$. É por não abdicar da tal "responsabilidade" que seu discurso diverge do de Cage: "em face do acaso por inadvertência, encontramos um acaso por automatismo,

15 "In Cage's terminology, 'chance' refers to the use of some sort of random procedure in the act of composition. [...] 'Indeterminacy, on the other hand, refers to the ability of a piece to be performed in substantially different ways - that is, the work exists in such a form that the performer is given a variety of unique ways to play it" (PRITCHETT, 1993, p. 108).

$16 \mathrm{Na}$ década de 50, uma calorosa discussão por diferentes compositores se travou em torno dos processos de utilização do acaso em música e seus desdobramentos estéticos. Selecionados em função da relevância de seus autores e da abrangência das questões colocadas, os textos Alea (1995) de Pierre Boulez, Indeterminacy (1958) e Experimental music (1958) de John Cage, serão confrontados neste artigo, a fim de discorrer de maneira breve, a respeito da perspectiva do acaso na Europa e na América. Mais especificamente: "[...] verificamos que há um consenso de que existem duas grandes tendências relativas ao emprego da indeterminação na música deste século. Estas tendências são diferenciadas a partir de critérios distintos: geográficos-culturais, manifestos por uma oposição entre Europa e os Estados Unidos da América; estéticos expressos por uma aceitação ou recusa da noção de obra de arte e dos princípios que ela envolve; linguísticos, relacionados ao problema de se/tido implicado na produção e na fruição da obra de arte" (TERRA, 2000, p. 136).

17 "A forma mais elementar da transmutação do acaso estaria na adoção de uma filosofia colorida de orientalismo que encobrisse uma fraqueza fundamental na técnica da composição; seria um recurso contra a asfixia da invenção, recurso de veneno sutil que destrói qualquer embrião de artesanato; eu qualificaria esta experiência - se é que isso é experiência, o indivíduo não se sentindo responsável por sua obra, simplesmente se atirando por fraqueza inconfessada, por confusão e por alívio temporário em uma espécie de magia pueril - eu qualificaria então essa experiência de acaso por inadvertência" (BOULEZ, 1995, p. 43).

\section{8}

REV. TULHA, RIBEIRÃO PRETO, v. 5, n. 1, pp. 9-32, jan.-jun. 2019 
automatismo puro ou automatismo no qual se introduz uma ideia de bifurcação vigiada" (BOULEZ, 1995, p. 46).

Em Boulez, o acaso no fazer interpretativo se torna um jogo de possibilidades nas quais as alternativas de execução estão muito bem definidas, determinando uma certa estrutura composicional. $\bigcirc$ compositor defende o uso do "acaso dirigido"l8, ou seja, submeter o acaso a um controle.

\begin{abstract}
É bom lembrar, porém, o quanto esta liberdade precisa ser dirigida, projetada, já que a imaginação 'instantânea' é mais suscetivel de falhas do que de iluminações; também, esta liberdade não trabalha sobre a invenção propriamente dita, mas sobre o pragmatismo da invenção (BOULEZ, 1995, p. 49).
\end{abstract}

Se para o compositor europeu, a introdução do acaso visa a ampliação do método serial e o uso do "acaso dirigido", para Cage, ela implica no rompimento com o determinismo a partir da necessidade de criar para si uma nova maneira de compor e executar uma obra musical. Como elemento essencial na retórica cageana, a superação da influência do compositor sobre a matéria sonora é fruto, praticamente, da não-interferência de sua personalidade e gosto estético sobre - resultado final da obra: "deve-se ceder ao desejo de controlar o som, limpar sua mente da música, e se dedicar a descobrir meios que permitam que os sons sejam eles mesmos no lugar de torná-los veículos de teorias feitas pelo homem ou da expressão de sentimentos humanos" (CACE, 1973, p. 10, tradução e grifo nosso) ${ }^{19}$. É a partir de então que o acaso se torna uma ferramenta que possui a virtude de gerar situações sonoras aparentemente livres de distorções subjetivas, além de configurar-se como ruptura de paradigmas musicais vigentes, o que

18 "Num conjunto dirigido, essas diversas estruturas devem ser obrigatoriamente controladas por um 'fraseado' geral, devem comportar sempre uma sigla inicial e um signo final, devem ainda apelar para certas espécies de 'plataformas' de bifurcação; isto para evitar uma perda total do sentido global da forma e também para impedir que se caia numa improvisação determinada apenas pelo livre-arbítrio" (BOULEZ, 1995, p. 49).

19 "(...) one may give up the desire to control sound, clear his mind of music, and set about discovering means to let sounds be themselves rather than vehicles for man-made theories or expression. Of human sentiments." (CACE, 1973, p. 10).

\title{
19
}

REV. TULHA, RIBEIRÃO PRETO, v. 5, n. 1, pp. 9-32, jan.-jun. 2019 
permite alinhar-se enquanto proposta ideológica afim à noção de liberdade.

A introdução do acaso em música por Cage, implica em uma desconstrução da própria noção de obra. $\bigcirc$ compositor prioriza o processo e não o resultado. Propõe situações musicais ao invés de impor. $\bigcirc$ processo abre a possibilidade de o intérprete identificar-se com qualquer eventualidade, afirmando o caráter não-intencional da obra. "E qual é o propósito de escrever música? Um deles, é claro, é não lidar com propósitos, mas lidar com sons. Ou a resposta deve assumir a forma de um paradoxo: uma não-intencionalidade intencional ou uma execução não-intencional". (CACE, 1973, p. 12, tradução nossa) ${ }^{20}$.

Assim sendo, os processos de utilização do acaso em música constituem uma das vertentes estético-composicionais desenvolvidas durante o século XX. Uma dessas tendências origina-se da assimilação do ruido como material composicional em obras como The Tides of Manaunaun (1912) e The Banshee (1925) de Henry Cowell, Threnody for The Victims of Hiroshima (1961) de Penderecki, tendendo para o advento da música eletroacústica. Outra, flui do tonalismo expandido para o pandiatonicismo do neoclassicismo, do minimalismo até o neorromantismo atual. E uma outra tendência, que surgiu com os sistemas alternativos de organização das alturas por processos seriais - por conjuntos, dodecafonismo e serialismo integral ${ }^{21}$ - mantém-se ativa ainda hoje. No entanto, a década de 1950 provocou reativamente o advento da indeterminação, tendência que intensificou a milenar prática da improvisação.

\footnotetext{
20 "And what is the purpose of writing music? One is, of course, not dealing with purpose but dealing with sounds. Or the answer must be take the form of paradox: a purposeful purposelessness or a purposeless play" (CACE, 1973, p. 12).

21 Inspirado pelas obras de Anton Webern, entre seus principais representantes encontravam-se Pierre Boulez, Karlheinz Stockhausen, Henri Posseur e Luigi Nono. Esta tendência eclodiu praticamente ao mesmo tempo que o uso do acaso em música. Dessa forma, o cenário do pós-guerra se dividia em dois grandes blocos, o dos serialistas e o dos não-serialistas. Esse conflito se reproduziu no Brasil, tendo no centro da cena o compositor nacionalista, Camargo Guarnieri e o então serialista, Hans-Joachim Koellreutter. "Os serialistas logo descobriram que, quanto mais predeterminavam certos aspectos de suas composições, mais eles eram forçados a renunciar ao controle sobre outros. Além disso, quanto mais preciso e complexo fosse o sistema de controle, mais difícil seria para os ouvintes perceberem sua influência no que realmente era ouvido; e assim, mais aleatório e arbitrário, o resultado parecia soar. A lógica estrutural elaborada não conseguiu produzir uma lógica aural correspondente" (MORGAN, 1993, p. 22, tradução nossa).
}

\section{0}

REV. TULHA, RIBEIRÃO PRETO, v. 5, n. 1, pp. 9-32, jan.-jun. 2019 
Como consequência desses desdobramentos, a lógica da escrita tradicional se revelou insuficiente para atender às novas filosofias e técnicas instrumentais, encorajando muito compositores a explorar métodos não convencionais. "Naturalmente, essa tendência não só exigia novos sinais de notação, mas uma atitude inteiramente nova em relação à notação como tal" (STONE, 1980, p. XVI, tradução nossa)22. De acordo com Morgan (1991, p. 376), o grau de multiplicidade em que a notação tradicional é modificada varia, obviamente, no quanto a música se afasta das práticas tradicionais. Portanto, novas grafias foram criadas partindo da necessidade de atualização da linguagem e da expressão musical oriundo dos novos procedimentos composicionais, principalmente os relacionados à indeterminação. No entanto, a variedade de novas práticas notacionais dificultou a aceitação de qualquer método único e as tentativas de padronização e codificação tiveram pouco sucesso ${ }^{23}$. Segundo Antunes (1989), ao padronizar a notação, padroniza-se o modo de pensar dos artistas, limita-se sua criatividade.

Como salienta Zampronha (2000), a notação musical é vista tradicionalmente como a utilização de signos gráficos estáveis, reversiveis e previsiveis, estabelecendo, portanto, uma relação de neutralidade com a matéria sonora, convertendo-a em seu estereótipo; só pode ser superada mediante a eliminação "da própria ideia de obra no sentido tradicional' (ibidem, p. 125). O rompimento com o conceito segundo o qual a notação é a obra implica em um novo paradigma que passa a ser a 'representação' da obra (SALLES, 2003, p. 90).

movimento que teve início nos Estados Unidos e na Europa na década de 1950 também repercutiu no Brasil. $\bigcirc$ uso de operações de acaso em música no Brasil foi introduzido pelos integrantes do grupo Música Nova de São Paulo, em meados de 1960. A organização dedicada a promover as músicas de seu tempo tinha em sua formação

22 "Naturally, this trend not only called for new notation signs, but for an entirely new attitude toward notation as such." (STONE, 1980, p. XVI).

23 De acordo com Antunes (1989), objetivou-se convencionar as novas grafias em congressos organizados pelo Istituto Italo Latino Americano di Cultura (Roma, 1971, 1973) e na Conferência Internacional organizada por Kurt Stone, no Instituut voor Psychoakoestiek en Elektronische Muziek (Bélgica, 1974). 
inicial os compositores Damiano Cozzella, Gilberto Mendes, Rogério Duprat e Willy Corrêa de Oliveira. A partir do conhecimento da música de John Cage, em Darmstadt, o grupo publica o Manifesto Música Nova na Revista Invenção24. Além dos quatro compositores citados acima, também assinaram: Régis Duprat, Sandino Hohagen, Júlio Medaglia e Alexandre Pascoal. O Manifesto tinha como tema central "o compromisso total com o mundo contemporâneo" e entre seus principais tópicos, o acaso em música se encontrava no "inter-relacionamento da música numa atividade interdisciplinar":

Música nova: procura de uma linguagem direta, utilizando os vários aspectos da realidade (física, fisiológica, psicológica, social, política e cultural) em que a máquina está incluída. Extensão ao mundo objetivo do processo criativo (indeterminação, inclusão de elementos 'alea', acaso controlado). (COZZELLA et al. apud MARIZ, 1983, p. 314).

No Brasil, a primeira obra a fazer uso dessa poética foi escrita em 1955 por um compositor que não pertencia ao grupo, mas que influenciou profundamente sua criação: Sistática de Hans-Joachim Koellreutter ${ }^{25}$.

\section{A performance musical na música indeterminada}

Com base na perspectiva apresentada, procuraremos trazer para um campo de discussões uma reflexão filosófica a respeito da performance musical de música indeterminada. Alguns questionamentos

24 Podemos encontrar a transcrição do Manifesto Música Nova em Mariz (1983, p. 313-315).

25 Fugindo da estética nacionalista predominante, alguns compositores da época, entre eles, Cláudio Santoro, Guerra Peixe, Eunice Catunda e Edino Krieger, aderiram ao grupo Música Viva (1939), liderado por Koellreutter. Para Neves (2008, p. 129), Koellreutter foi um "[...] organizador dinâmico dos movimentos de renovação e o líder absoluto da nova geração de compositores brasileiros, que poderiam, assim, libertar-se da orientação unilateral e exclusiva do nacionalismo". O compositor introduziu o dodecafonismo no Brasil, entre os anos de 1965 a 1975. Após residir em países como Japão e Índia, Koellreutter criou aquilo que dizia ser a "estética relativista do impreciso e paradoxal, [...] visto como a superação da dualidade de contrários aparentemente opostos" (KOELLREUTTER, 1987, p. 36). 
foram levantados: ( 1 ) qual o papel do performerna música indeterminada? (2) Como se dá o controle do compositor sobre o resultado final da obra? (3) E considerando o papel mais ativo do performer, influindo criativamente sobre o resultado final da obra, a quem pertence sua autoria?

Entre as recentes produções de música instrumental podemos notar algumas composições assinaladas por uma característica comum: a peculiar autonomia executiva concedida ao intérprete, o qual não só dispõe da liberdade de interpretar as indicações do compositor conforme sua sensibilidade pessoal (como se dá no caso da música tradicional), mas também deve intervir na forma da composição, não raro estabelecendo a duração das notas ou a sucessão dos sons, num ato de improvisação criadora (ECO, 2003, p. 37).

A autonomia executiva cedida ao intérprete pode variar de diversas maneiras. Os elementos que são deixados à deriva da indeterminação podem ser a escolha do material sonoro; os elementos de expressão (andamento, dinâmica, articulação e acentuação); elementos de duração (tempo, ritmo); altura, silêncio e forma. Na prática, estes elementos podem aparecer sozinhos ou em combinações, conferindo à performance novas possibilidades de conexão. "A liberdade [...] não é dada para permitir qualquer coisa que se queira fazer, trata-se de um convite para que as pessoas se libertem de seus gostos e desgostos pessoais e se disciplinem" (CACE apud KOSTELANETZ, 2003, p. 108).

Costa (2012) utiliza o termo estratégia de invariância para se referir a todo o "desejo de que determinados itens se repitam a cada execução de uma peça, [...] no sentido de diminuir a probabilidade de que determinados itens musicais considerados essenciais ao projeto composicional deixem de figurar o resultado final" (COSTA, 2009, p. 54). A presença dessas estratégias "aumentam as chances de que se formem, para a obra, limites morfológicos que a diferenciem de um entorno de aspecto distinto" (COSTA apud COSTA, 2018, p. 163).

Logo, a obra é definida em parâmetros de interpretação voltados à casualidade e à níveis indeterminação de resultados. A liberdade concedida ao intérprete não pode ser considerada infinita e muito 
menos imprecisa. Estes parâmetros são caracterizados por um contorno suficientemente definido, prefixado e condicionado, conferindo limites ao fazer artístico. "Estamos ainda fora de uma situação de liberdade interpretativa, uma vez que os resultados são medidos em função da expectativa do compositor" (COSTA, 2017, p. 12).

Essa definição compreende as diversas formas de notação musical: partituras, gráficos, instruções, dados impressos uma fita ou mídia digital; compreende ações afirmativas que visem estimular determinado efeito: escolha criteriosa de intérpretes, direção de ensaios e performance, todo tipo de regra transmitida oralmente; e compreende ainda formas de controle de caráter intersubjetivo ou social tais como influência, reputação, repetição de modelos considerado válidos, observância de regras estilísticas definidas por especialistas, etc. (COSTA, 2011 , p. 6).

Muitas reflexões filosóficas foram feitas sobre a abertura nas artes. Para este trabalho consideraremos as obras A Teoria da Formatividade (1993) de Luigi Pareyson e Obra Aberta de Umberto Eco, que possui estreita relação com a anterior. Na coletânea de ensaios lançados em 1962, Umberto Eco afirma que o pressuposto fundamental da arte é a abertura, conferindo um espaço relativamente importante à discussão da arte musical. Após recorrer à diversas fontes com o intuito de defender o princípio básico de que todas as formas nas artes são abertas, o autor sustenta que em virtude da fruição pessoal a obra jamais poderá ser totalmente determinada.

autor produz uma forma acabada em si, desejando que a forma em questão seja compreendida e fruída tal como a produziu; todavia, no ato de reação à teia dos estímulos e de compreensão de suas relações, cada fruidor traz uma situação existencial concreta, uma sensibilidade particularmente condicionada, uma determinada cultura, gostos, tendências, preconceitos pessoais, de modo que a compreensão da forma originária se verifica segundo uma determinada perspectiva individual (ECO, 2003, p. 40). 
Luigi Pareyson, por sua vez, analisa a obra de arte a partir de um ponto de vista "formativo" - a obra como um objeto em construção, encontrando-se em permanente formação. Constituída pelo processo formativo (a ação de formar) e pelo formante (o sujeito que exerce a ação de formar), todo ato do formante define-se em processo formativo, característica qualitativa pessoal, abarcando suas particularidades, retratando-o e exprimindo-o no processo e resultado final. A Teoria da Formatividade também não se limita a uma atividade artística específica, sendo possivel relacionar sua obra de maneira bastante estreita com o ato da performance musical.

Para Pareyson (1993, p. 181 ) "a interpretação é um conhecimento em que o objeto se revela na medida em que o sujeito se exprime”. Desse modo, toda interpretação assume um caráter pessoal e subjetivo, onde não há critério de juízo, tornando-as igualmente legítimas. "Entendese porque a interpretação é, geralmente, qualificada pelo possessivo, 'minha, tua, sua interpretação', sempre personalíssima, por isso múltipla" (PAREYSON, 1997, p. O I). Assim, a participação do formante no processo formativo é identificada como um operar em conjunto através de estímulos entre compositor-intérprete.

Todas as interpretações são definitivas no sentido de que cada uma delas é, para o intérprete, a própria obra, e provisórias, no sentido de que cada intérprete sabe da necessidade de aprofundar continuamente a própria interpretação. Enquanto definitivas, as interpretações são paralelas, de sorte que uma exclui as outras embora sem negá-las: cada uma delas é um modo pessoal e por isso irredutível de penetrar e dar a vida a uma mesa obra (PAREYSON, 1993, p. 223).

O caráter pessoal e subjetivo de uma performance é caracterizado por um contexto sociocultural, pois a percepção que temos de determinado objeto não é fato natural e único, mas dependente de determinados modelos de cultura, hábito, convicção e sensibilidade, que são efeitos "de uma educação devida ao ambiente natural, histórico e social” (ECO, 2003, p. 1 39). Para Eco (2003, p. 40) "cada fruição é, assim, uma interpretação e uma execução, pois cada fruição a obra revive dentro de uma perspectiva original". 
Na pessoa se podem encontrar dois aspectos: a totalidade e o desenvolvimento. Por um lado, com efeito, a pessoa é, em cada um de seus instantes, uma totalidade infinita e definida, fixa em uma forma singularíssima e inconfundivel dotada de uma validade concluída e reconhecivel; e, por outro, é um variar contínuo, aberto à possibilidade de contestações e reelaborações, de revisões e enriquecimentos, de repetições de velhos motivos e novos atos. (PAREYSON, 1993, p. 176).

Para Costa (201 1, p. 5) "a obra musical, morfologicamente falando, é frágil, porque nada garante que as indicações presentes numa partitura ou em qualquer outra forma de orientação, serão suficientes para que o projeto composicional se realize"26. Sua execução depende de um trabalho de partilha intersubjetiva. A obra é motivada pelo compositor e dependente de seus intérpretes para ganhar existência. Por conta disso, ao executá-la é importante que o trabalho do compositor seja significante para o intérprete, que fazendo uso dos estímulos visuais da partitura, confere significado à mesma, produzindo um sentido antes oculto.

Pareyson acredita que existem duas atitudes essenciais a fim de alcançar êxito na interpretação: interesse e respeito. "Graças ao interesse o interpretante se torna capaz de interrogar as coisas, e graças ao respeito é capaz de escutá-las" (PAREYSON, 1993, p. 203) Portanto, é necessário haver diálogo entre performer e a obra, a denominada leitura, ação de estudo, análise e interpretação do sujeito para com o objeto, especificamente nas obras indeterminadas, já que esta tendência estético-composicional não possui um princípio único de regras, técnicas e métodos de composição e execução de uma obra.

De acordo com Pareyson (1993), o concluir da performance se dá quando o fruidor atinge a imobilidade. A imobilidade é alcançada por um momento de contemplação da obra. A contemplação, por sua vez, é o agir do sujeito sobre o concluir de um processo de interpretação, em que este acarretou tensão, desejo, tentativa e esforço. "Como se viu,

26 Segundo COSTA (2017) entende-se por morfologia da obra musical o projeto composicional acabado, fixado em partitura, com suas particularidades formais. A morfologia é dada a priori, prerrogativa individual do autor e seria responsabilidade do intérprete transmiti-la através da sua execução, da forma mais íntegra possivel, ao ouvinte. Busca-se uma coincidência morfológica entre o dado notacional e o resultado sonoro como se ambos estivessem atados por uma perfeita causalidade.

\section{6}

REV. TULHA, RIBEIRÃO PRETO, v. 5, n. 1, pp. 9-32, jan.-jun. 2019 
o movimento da interpretação é um processo de formação, e o repouso em que culmina a interpretação é contemplação" (PAREYSON, 1993, p. 186).

\begin{abstract}
[...] notamos a tendência de fazer com que cada execução da obra nunca coincida com uma definição última dessa obra; cada execução a explica mas não a esgota, cada execução realiza a obra mas todas são complementares entre si, enfim, cada execução nos dá a obra de maneira completa e satisfatória mas ao mesmo tempo no-la dá incompleta, pois não nos oferece simultaneamente todos os demais resultados com que a obra poderia identificar-se (ECO, 2003, p. 57).
\end{abstract}

$\bigcirc$ resultado alcançado não é definitivo, nem único. $\bigcirc$ resultado é escolhido dentre outros também possíveis num campo de múltiplas possibilidades interpretativas. Ao aprofundar-se, refinando sua interpretação, o performer em um perpétuo movimento de revisão, visa uma melhor adequação de sua interpretação perante o objeto de estudo. Assim, todo resultado sonoro é passivel de uma nova releitura e aprofundamento, em que a cada releitura o processo de interpretação e seus resultados são alterados.

\begin{abstract}
É provável que uma obra [...] graças a fatores subjetivos (tais como a recorrência a clichês, as idiossincrasias dos intérpretes a referência à performance de outros trabalhos do autor em questão, à imitação de algum modelo considerado representativo, além de fatores objetivos já referidos anteriormente), adquira uma relativa estabilidade morfológica depois de uma série de execuções (COSTA, 2012, p. 2).
\end{abstract}

Contudo, podemos perceber que a liberdade delegada ao intérprete instiga e confere um perfil democrático na composição musical, que agora se torna menos baseada em técnicas e regras de composição tradicionais, convencionadas histórica e culturalmente, e mais decorrente de uma poética. "Em estética, diremos nós, essa constatação é bem mais antiga, pois a relação entre intérprete e obra foi sempre uma relação de alteridade" (ECO, 2003, p.33).

\title{
27
}

REV. TULHA, RIBEIRÃO PRETO, v. 5, n. 1, pp. 9-32, jan.-jun. 2019 
À luz dos critérios da música tradicional ocidental, a democratização e a colaboração entre compositor e intérprete permitem a partilha da criação, mas nega o compartilhamento de propriedade que, ainda assim, pertence a um autor individual. $\bigcirc$ compositor dá origem à obra, confecciona o texto musical e sobre ela exerce o direito de propriedade, atribuindo a si mesmo o poder de julgamento sobre a interpretação de qualquer performance. A concepção de que seria do intérprete a prerrogativa de coautoria da obra não procede, "pois ele está implicado no processo mais como um operador que, no caso, acumularia as tarefas de 'gerador de randomismo' e de executante" (COSTA, 2017, p. 12).

\begin{abstract}
É forçoso reconhecer [...] que é sequestrada mais uma dimensão do processo criativo do intérprete e que a impressão de que algo foi elaborado por ele se deve mais ao fato de que a partitura foi produzida por um ato seu do que por suas ideias musicais interferirem no resultado sonoro (COSTA, 2017, p. 12).
\end{abstract}

\title{
5. Conclusão
}

Os processos de utilização do acaso em música foi uma das tendências estético-composicionais mais influentes na música da segunda metade do século XX. Caracterizando-se por oferecer ao intérprete diferentes níveis de liberdade interpretativa, a indeterminação em música é uma tendência estético-composicional que se move à procura de um discurso que tem como fim diferentes possibilidades interpretativas. Aqui, o compositor não está mais interessado na singularidade da permanência da obra e sim, na singularidade do momento de execução.

Minha experiência junto à performance de música indeterminada e à pesquisa foi e é um rico campo de questionamentos. Daqui surgiram as perguntas supracitadas que motivaram a elaboração deste trabalho: (1) qual o papel do performer na música indeterminada? (2) Como se dá o controle do compositor sobre o resultado final da obra? (3) E considerando o papel mais ativo do performer, influindo criativamente 
sobre o resultado final da obra, a quem pertence sua autoria? $\mathrm{Na}$ busca de respostas, temas contextuais tornaram-se necessários.

Discutimos de maneira breve a genealogia do conceito de obra musical até sua cristalização por volta de 1800, destacando a influência decisiva no desenvolvimento da notação e performance musical. Abordamos as transformações estético-composicionais que surgiram a partir da segunda metade do século XX e a pluralidade de vertentes existentes a partir dos processos de utilização do acaso. E refletimos sobre a construção de sentido na performance musical pela perspectiva do intérprete através dos trabalhos de Luigi Pareyson (1993) e Umberto Eco (2003).

Ao fim deste trabalho, percebo que a partitura da música de concerto ocidental se tornou a própria manifestação da obra, levandonos a um imaginário dualista: compositor/intérprete e obra/performance. No entanto, o advento da indeterminação nos trouxe importantes transformações e reflexões que implicaram na desconstrução da própria noção de obra, resultando em um novo olhar sobre o fazer musical, seja ele compositivo e/ou interpretativo. Essa nova poética "diluiu a suposição do dualismo abstrato/concreto e a segregação entre compositor, intérprete e ouvinte, que passam a ser compreendidos como agentes colaboradores e co-criadores" (ALMEIDA, 2011, 69).

Diante disso, torna-se necessário ampliar o número de discussões e reflexões a respeito dessa prática musical. Segundo Deltrégia (1991), a ausência de trabalhos dedicados a refletir sobre essa poética se reflete, por exemplo, na performance nem sempre adequada desse repertório. Diversos motivos têm colaborado para a situação no Brasil (mas não somente aqui): a formação tradicional de professores e intérpretes, criando um ciclo didático-pedagógico vicioso; o mercado editorial restrito para novas obras, impondo dificuldades financeiras na edição e na divulgação das mesmas; e a situação em que se encontra a maioria dos compositores atuais, distantes do ensino instrumental. 


\section{Referências}

ALMEIDA, Alexandre Zamith. Por uma visão de música como performance. Opus, Porto Alegre, v. 17, n. 2, p. 63-76, dez. 2011.

ANTOKOLETZ, Elliott. Twentieth-Century Music. Englewood Cliffs: Prentice Hall, 1992.

ANTUNES, Jorge. Notação na música contemporânea. Brasilia: Sistrum, 1989.

BOULEZ, Pierre. Apontamentos de aprendiz. São Paulo: Editora Perspectiva, 1995.

CACE, John. Silence: Lectures and writings by John Cage. Hanover: Uesleyan University Press, 1973.

COSTA, Valério Fiel da. Comentários sobre a possibilidade de autopoiese da obra musical e sobre o performer como seu componente sistêmico. Debates, Rio de Janeiro, v. 1, n. 2 1, p. 155-178, nov. 2018.

O lugar da performance na música indeterminada cageana. Revista Música Hodie, Goiânia, V.17 - n. 1, 2017, p. 07-18.

O "quanto' e o "como" da obra enquanto critério de análise morfológica: um estudo de caso. In: XXII Congresso da ANPPOM, João Pessoa, 2012, p. 1-8.

Considerações sobre a forma em peças de caráter aberto de Cage e Stockhausen. In: XXI CONCRESSO DA ANPPOM, Uberlândia, 2011, p. $1-8$.

Da indeterminação à invariância: Considerações sobre a morfologia musical a partir de peças de caráter aberto. 197 f. Tese (Doutorado) - Unicamp, Campinas, 2009.

COOK, Nicholas. Beyond the Score: Music as Performance. Oxford: Oxford University Press, 2013. 
DELTRÉCIA, Claudia Fernanda. $\bigcirc$ uso da música contemporânea na iniciação ao piano. 1999. 2v. Dissertação (Mestrado em Artes) Unicamp, Campinas, 1999.

ECO, Umberto. Obra Aberta: Forma e indeterminação nas poéticas contemporâneas. 9. ed. São Paulo: Perspectiva, 2003.

COEHR, Lydia. The Imaginary Museum of Musical Works: An Essay in the Philosophy of Music. Oxford: Clarendon Press, 1992.

KOELLREUTTER, Hans-Joachim. Introdução a estética e à composição musical contemporânea. Org.: Bernadete Zagonel e Salete M. La Chiamulera. Porto Alegre: Movimento, 1987 2003.

KOSTELANETZ, Richard. Conversing with Cage. New York: Routledge, Review Press, 1993.

MARIZ, Vasco. Historia da música no Brasil. Rio de Janeiro: Civilização Brasileira, 1983.

MORGAN, Robert. Twentieth-Century Music: A History of Musical Style in Modern Europe and America. New York: W. W. Norton, 1991.

MORGAN, Robert (Ed.). Modern Times: From World War I to the present. Basingstoke: The Macmillan Press Limited, 1993.

NEVES, José Maria. Música Contemporânea Brasileira. Rio de Janeiro: Contracapa, 2008. 1997.

PAREYSON, Luigi. Os problemas da estética. São Paulo: Martins, Teoria da formatividade. Petrópolis: Vozes, 1993.

PRITCHETT, James. The music of John Cage. New York: Cambridge University Press, 1993. 
SALLES, Paulo de Tarso. Aberturas e Impasses: $\bigcirc$ pós-modernismo na música e seus reflexos no Brasil - 1970-1980. São Paulo: Editora Unesp, 2003.

SMALL, Christopher. Musicking: The Meaning of Performing and Listening. Hanover, London: Uesleyan University Press, 1998.

STONE, Kurt. Music Notation in the Twentieth Century. New York: W. W. Norton \& Company, 1980.

TERRA, Vera. Acaso e aleatório na música: um estudo da indeterminação nas poéticas de Cage e Boulez. São Paulo: EDUC/ FAPESP, 2000.

WIORA, Walter. The four ages of music. New York: W. W. Norton E Company, Inc., 1965.

\section{Sobre a autora}

Ana Leticia Crozetta Zomer é doutoranda em Teoria e Análise Musical (2018) pela Universidade de São Paulo (USP), sob orientação da Prof. Dr. Adriana Lopes da Cunha Moreira; Mestre em Musicologia e Etnomusicologia (2017), sob orientação do Prof. Dr. Guilherme Antonio Saverbronn de Barros; e Graduada em Música (2013), pela mesma instituição. Sua pesquisa tem por finalidade discutir o emprego de operações de acaso e indeterminação na música de compositores brasileiros, mais especificamente, em obras do repertório violinístico a partir de 1950. Atua nos seguintes temas: Análise musical; Músicas do século XX e XXI; Acaso e Indeterminação; John Cage; Repertório violinístico.

Recebido em $31 / 07 / 2019$

Aprovado em 26/08/2019 